\title{
Dopamine D1-Class Receptors Selectively Modulate a Slowly Inactivating Potassium Current in Rat Medial Prefrontal Cortex Pyramidal Neurons
}

\author{
Yan Dong ${ }^{1}$ and Francis J. White ${ }^{2}$ \\ Departments of ${ }^{1}$ Neuroscience and ${ }^{2}$ Cellular and Molecular Pharmacology, Finch University of Health Sciences/The Chicago Medical School, North Chicago, \\ Illinois 60064
}

The dopamine (DA) innervation of medial prefrontal cortex (mPFC) regulates cognitive activity in a complex manner. Alterations of DA function, particularly via the DA D1 receptor class (D1R), are implicated in both schizophrenia and drug addiction, yet the precise roles of DA in modulating mPFC excitability remain unclear. We focused on DA modulation of voltage-gated $\mathrm{K}^{+}$current (VGKC) in acutely dissociated rat MPFC pyramidal neurons. We defined three components of the whole-cell VGKC according to biophysical and pharmacological properties. The A-type current $\left(I_{A}\right)$, with rapid activation and inactivation kinetics, was completely inactivated by prolonged holding of the membrane potential at $-40 \mathrm{mV}$ and was sensitive to the $\mathrm{K}^{+}$channel blocker 4-aminopyridine (4-AP) but not tetraethylammonium (TEA) or dendrotoxin (DTX). The slowly inactivating $\mathrm{K}^{+}$current $\left(I_{D}\right)$, with rapid activation but relatively slow inactivation, was the major contributor to VGKC and was completely inactivated at $-40 \mathrm{mV}$ and sensitive to TEA and DTX but less so to 4-AP. The very slowly inactivating $\mathrm{K}^{+}$current $\left(I_{K}\right)$ was elicited by command steps to more depolarized potentials from a prolonged holding potential of $-40 \mathrm{mV}$ and was sensitive to all three blockers. Stimulation of DA D2 receptors failed to alter any component of whole-cell VGKC. Stimulation of DA D1Rs selectively suppressed $I_{D}$, an effect mimicked by the adenylyl cyclase activator forskolin, the active cAMP analog Sp-cAMP, and the protein phosphatase inhibitor okadaic acid. Inhibition of protein kinase A (PKA) with either PKI or Rp-cAMP abolished D1R modulation. Thus, the DA D1R/cAMP/PKA signaling pathway mediates modulation of $I_{D}$ by DA in rat mPFC pyramidal neurons.

Key words: dopamine; prefrontal cortex; potassium current; dopamine D1 receptors; drug addiction; schizophrenia

\section{Introduction}

The prefrontal cortex (PFC) is a major association area connected to all areas of neocortex and to various allocortical, limbic, and other regions. This provides the PFC the ability to prioritize and reference stimuli to internal representations, direct attention, and monitor temporal event sequencing (Fuster, 2001; Miller and Cohen, 2001). Dopamine (DA) is essential for proper information processing in the PFC (Goldman-Rakic et al., 2000). In particular, an optimal level of DA D1-class receptor (D1R) stimulation is required. When PFC D1R stimulation is either significantly reduced or augmented, disruption of working memory results (Sawaguchi and Goldman-Rakic, 1991; Williams and Goldman-Rakic, 1995; Zahrt et al., 1997; Seamans et al., 1998).

The mesocortical DA projection arises primarily from the ventral tegmental area (VTA) and terminates mainly on pyramidal neurons in deep layers V and VI of medial PFC (mPFC)

Received Sept. 23, 2002; revised Jan. 9, 2002; accepted Jan. 10, 2002.

This work was supported by United States Public Health Service Grant DA 12618 and Senior Scientist Award DA 00456 from the National Institute on Drug Abuse (F.J.W.). We thank Lori Baker and Kerstin Ford for excellent technical assistance, Dr. Robert Foehring for his critical comments on this manuscript, and Drs. Donald C. Cooper, D. James Surmeier, and Xiu-Ti Hu for expert advice.

Correspondence should be addressed to Dr. Francis J. White, Department of Cellular and Molecular Pharmacology, Finch University of Health Sciences/The Chicago Medical School, 3333 Green Bay Road, North Chicago, IL 60064 E-mail: francis.white@finchcms.edu.

Y. Dong's present address: Department of Psychiatry, Stanford University School of Medicine, Palo Alto, CA 94304-5485.

Copyright $\odot 2003$ Society for Neuroscience $\quad 0270-6474 / 03 / 232686-10 \$ 15.00 / 0$
(Bjorklund et al., 1978; Emson and Koob, 1978; Berger et al., 1991; Carr et al., 1999). Many of these neurons project to the VTA and nucleus accumbens, providing the means by which the PFC can modulate the mesoaccumbens DA system (Sesack and Pickel, 1992; Carr and Sesack, 2000). Alterations of DA function within these systems have been implicated in various neuronal disorders, particularly schizophrenia (for review, see Lewis, 1995; Knable and Weinberger, 1997) and drug addiction (for review, see Vanderschuren and Kalivas, 2000; Tzschentke, 2001).

Despite clear evidence that DA modulates behavioral output from the PFC, specific knowledge of the mechanisms by which DA alters the activity of PFC pyramidal neurons remains limited. Indeed, the electrophysiological actions of DA within the PFC have long been an enigma (for review, see Yang et al., 1999). Recent current- and voltage-clamp recordings have begun to provide clues about the targets of DA modulation. DA was reported to decrease persistent $\mathrm{Na}^{+}$current in mPFC pyramidal neurons (Geijo-Barrientos and Pastore, 1995), although others observed the opposite effect (Yang and Seamans, 1996; Gorelova and Yang, 1997) or no modulation (Maurice et al., 2001). DA D1R stimulation was recently shown to suppress the transient $\mathrm{Na}^{+}$current in acutely dissociated rat mPFC neurons (Maurice et al., 2001) and to remove outward rectification in PFC neurons recorded in brain slices (Yang and Seamans, 1996; Gorelova and Yang, 1997). A decrease in excitability of PFC neurons has recently been attributed to DA D2-class receptor (D2R) stimulation (Gulledge and Jaffe, 1998). 
Here we focused on DA receptor modulation of voltage-gated $\mathrm{K}^{+}$currents (VGKCs) in acutely dissociated rat mPFC pyramidal neurons. VGKCs are responsible for setting the resting potential, repolarizing and hyperpolarizing the cell, and shaping voltage trajectories in the subthreshold voltage range for action potentials (Hille, 2001). As such, they may provide a specific target by which DA may regulate cognitive function.

\section{Materials and Methods}

Acute dissociation. Pyramidal neurons from mPFC layers V and VI were acutely dissociated from brain slices obtained from 4- to 5-week-old rats. Rats were anesthetized with methoxyflurane (Mallinckrodt Veterinary Incorporated, Mundelein, IL) and decapitated. Brains were quickly removed, blocked, and sliced on a DSK microslicer (Campden Instrument) in a $1-2^{\circ} \mathrm{C}$ sucrose solution containing (in $\mathrm{mm}$ ): 234 sucrose, $2.5 \mathrm{KCl}, 1$ $\mathrm{Na}_{2} \mathrm{HPO}_{4}, 11$ glucose, $4 \mathrm{MgSO}_{4}, 0.1 \mathrm{CaCl}_{2}$, and 15 HEPES, pH 7.3, 300 $\mathrm{mOsm} / \mathrm{l}$. Coronal slices $(400 \mu \mathrm{m})$ were incubated for $1-4 \mathrm{hr}$ at room temperature in a sodium bicarbonate-buffered Earle's balanced salt solution bubbled with $95 \% \mathrm{O}_{2} / 5 \% \mathrm{CO}_{2}$ and containing (in $\mathrm{mm}$ ): 1 kynurenic acid, 1 pyruvic acid, $0.1 \mathrm{~N}$-nitroarginine, and 0.005 glutathione, $\mathrm{pH}$ 7.4, $300 \mathrm{mOsm} / \mathrm{l}$. Individual slices were placed in a $\mathrm{Ca}^{2+}$-free buffer containing (in mM): $140 \mathrm{Na}$-isethionate, $2 \mathrm{KCl}, 4 \mathrm{MgCl}_{2}, 23$ glucose, and 15 HEPES, pH 7.4, $300 \mathrm{mOsm} / \mathrm{l}$, and the $\mathrm{mPFC}$ was isolated under a dissecting microscope. The mPFC tissue was then placed into an oxygenated, HEPES-buffered HBSS containing $1.5 \mathrm{mg} / \mathrm{ml}$ protease (type $\mathrm{XIV}$ ) at $35^{\circ} \mathrm{C}$ for $30 \mathrm{~min}$. The enzyme chamber also contained (in $\mathrm{mm}$ ): 1 kynurenic acid, 1 pyruvic acid, $0.1 \mathrm{~N}$-nitroarginine, and 0.005 glutathione, $\mathrm{pH} 7.4,300 \mathrm{mOsm} / \mathrm{l}$.

After enzymatic treatment, the tissue was rinsed several times in $\mathrm{Ca}^{2+}$. free buffer and triturated with a graded series of fire-polished Pasteur pipettes. The cell suspension was placed in a $35 \mathrm{~mm}$ Lux Petri dish (Nunc, Naperville, IL), which was mounted on an inverted microscope. Cells were then given several minutes to settle before recording.

Whole-cell recordings. Whole-cell recordings were performed using standard techniques. Electrodes were pulled from Corning (Corning, NY) 7052 glass (Flaming/Brown P-97 puller; Sutter Instrument Co., Novato, CA) and fire-polished (MF-83 microforge; Narishige, Hempstead, $\mathrm{NY)}$ just before use. The intracellular recording solution for recording outward $\mathrm{K}^{+}$currents contained (in $\mathrm{mM}$ ): $60 \mathrm{~K}_{2} \mathrm{SO}_{4}, 60 \mathrm{~N}$-methylglucamine, 10 HEPES, 5 BAPTA, 12 phosphocreatine, 3 MgATP, 0.2 $\mathrm{Na}_{3} \mathrm{GTP}, 2 \mathrm{MgCl}_{2}$, and $0.5 \mathrm{CaCl}_{2}, \mathrm{pH} 7.2,275 \mathrm{mOsm} / \mathrm{l}$. The normal extracellular recording solution contained (in $\mathrm{mm}$ ): $140 \mathrm{Na}$-isethionate, 10 HEPES, 12 glucose, 17.5 sucrose, $1-4 \mathrm{KCl}, 4 \mathrm{MgCl}_{2}, 0.01 \mathrm{TTX}, \mathrm{pH}$ 7.35, $300 \mathrm{mOsm} / \mathrm{l}$. All reagents were obtained from Sigma (St. Louis, MO) except ATP and GTP (Boehringer Mannheim, Indianapolis, IN); BAPTA, Sp-8-Brom-cAMP, Rp-cAMP, H8, active and inactive forskolin, and okadaic acid (OA) were from Calbiochem (La Jolla, CA). Extracellular recording solutions were applied via one of a series of four glass capillaries $(\sim 250 \mu \mathrm{m}$ inner diameter $)$ in which gravity-fed flow was regulated by electronic valves (Bio-logic). Recordings were obtained with an Axon Instruments (Foster City, CA) 200A patch-clamp amplifier and controlled and monitored with a Pentium PC running pCLAMP (version 8.0) with a $125 \mathrm{kHz}$ interface (Axon Instruments). Electrode resistances were $\sim 1-4 \mathrm{M} \Omega$ in bath. After formation of the gigaohm seal and subsequent cell rupture, series resistance was compensated (70-80\%) and periodically monitored. Recordings were restricted to neurons with pyramidal soma and small remnants of the apical dendrites. The neuron was not included in analysis unless its whole-cell capacitance was between 8 and $14 \mathrm{pF}$ and its series resistance was below $8 \mathrm{M} \Omega$ and steady $(<10 \%$ oscillation). Recordings were performed at room temperature $\left(22-24^{\circ} \mathrm{C}\right)$.

Data analysis. Decay time constants were determined by fitting current recording with single, double, or triple exponential functions of the form $I=A_{0}+A_{1} \exp \left(-t / \tau_{1}\right)+A_{2} \exp \left(-t / \tau_{2}\right)+A_{3} \exp \left(-t / \tau_{3}\right) \cdot A_{0}$ to $A_{3}$ are amplitude coefficients. $\tau_{1}$ to $\tau_{3}$ refer to time constants. Dose-response data were fit with a Langmuir isotherm of the form $C /\left(C+\mathrm{IC}_{50}\right)$, where $C$ is the concentration of blockers. A two-site model of pharmacological blockade was fit with $I / I_{\max }=A /[1+\operatorname{EXP}(\operatorname{LOG}(C) / B)]+(1-A) /[1+$
$\operatorname{EXP}(C) / D]$, where $C$ is the concentration of blockers, and $B$ and $D$ are two $\mathrm{IC}_{50}$ values. Recovery of VGKC was fit with $I / I_{\max }=\mathrm{A} \times[1-$ $\left.\operatorname{EXP}\left(-t / \tau_{1}\right)\right]+(1-A) /\left[1-\operatorname{EXP}\left(-t / \tau_{2}\right)\right]$, in which $I$ is the current, $t$ is time, and $\tau_{1}$ and $\tau_{2}$ are the time constants of recovery from inactivation. Statistica (Statsoft, Tulsa, OK) was used for statistical analysis. Origin (Microcal Northampton, MA) was used to plot the current traces and graphs. Box-whisker was used to plot most of the graph presentation because of the small sample size. The box plot presented the distribution as a box, with the median as a central line and the hinges as the edge of the box, which divided the top and bottom halves of the distribution in two. The inner fence, started from the edge of the box, runs to the limits of the distribution, excluding outliers, which are defined as points that are two times the interquartile range beyond the inner fence. The outliers are shown as open circles. The averaged data are typically shown as mean $\pm \mathrm{SE}$.

\section{Results}

\section{Three components of VGKC in mPFC pyramidal neurons}

Whole-cell VGKC was elicited in MPFC neurons using multiple protocols. In a protocol with short depolarization duration, the membrane potential was held at $-70 \mathrm{mV}$. A hyperpolarization prepulse $(2 \mathrm{sec})$ to $-100 \mathrm{mV}$ was used to deinactivate inactivated $\mathrm{K}^{+}$channels that could not be recovered by holding at $-70 \mathrm{mV}$. The following $100 \mathrm{msec}$ depolarization steps (from -100 to +30 $\mathrm{mV}$ with $10 \mathrm{mV}$ increments) elicited the whole-cell VGKC (Fig. $1 A)$. This protocol elicited similar traces in most of the recorded neurons ( $n=16$ of 20) in which whole-cell current showed a rapid activation and slow inactivation. A fast inactivating component was observed in $20 \%$ of the recorded neurons $(n=4$ of 20) (Fig. $2 A$ ), as discussed later. Depolarization steps inactivated whole-cell currents as shown in Figure $1 B(n=6)$. The membrane potential was held at $-70 \mathrm{mV}$. The current that was elicited by a test step to $+30 \mathrm{mV}$ showed a voltage-dependent inactivation after the $600 \mathrm{msec}$ prepulse (stepped from -100 to $+30 \mathrm{mV}$ with $10 \mathrm{mV}$ increments). We chose this short prepulse to generate a pseudo-steady-state inactivation instead of true steady-state inactivation for technical convenience. The peak current-voltage $(I-V)$ curve is summarized in Figure 1C. Whole-cell VGKC in this neuron began to activate at $-60 \mathrm{mV}$, suggesting that VGKC may be activated at physiological resting membrane potentials $(-70$ to $-50 \mathrm{mV})$. A different set of protocols (Fig. $1 D, E$ ) was used to isolate individual components of VGKC by taking advantage of their inactivating kinetics. The membrane potential was held at $-70 \mathrm{mV}$. The first protocol started with a hyperpolarization prepulse $(4 \mathrm{sec})$ to $-100 \mathrm{mV}$, which deinactivated most inactivated $\mathrm{K}^{+}$channels. The following 4 sec test steps from -70 to $+30 \mathrm{mV}$ (at $10 \mathrm{mV}$ increments) elicited the whole-cell current $(n=5)$ (Fig. 1D). The second protocol started with a depolarization prepulse $(10-20 \mathrm{sec},-40 \mathrm{mV})$, which inactivated components of the current with relatively short inactivation kinetics (several seconds). The following test steps (from -70 to $+30 \mathrm{mV}$ at $10 \mathrm{mV}$ increments) elicited relatively small currents with little inactivation $(n=5)$ (Fig. $1 E$ ). We operationally defined these noninactivating traces as $I_{K}$. This current did not change when extracellular $\mathrm{Cl}^{-}$was replaced by gluconate $(n=4$; data not shown), excluding involvement of $\mathrm{Cl}^{-}$channels. The slowly inactivating current was obtained (Fig. $1 F$ ) after subtraction of $I_{K}$ from the whole-cell currents shown in Figure $1 D$. This current activated rapidly and inactivated slowly and was operationally termed $I_{D}$. The $I-V$ relationship of $I_{K}$ and $I_{D}$ are plotted in Figure $1 G$. Both currents begin to activate at approximately $-40 \mathrm{mV}$ ( $n=5$ for each group).

In $20 \%$ of the recorded neurons $(n=4$ of 20$)$, the protocol shown in Figure $1 A$ elicited a whole-cell current with a rapid (several milliseconds) inactivating component (Fig. 2A). Because 

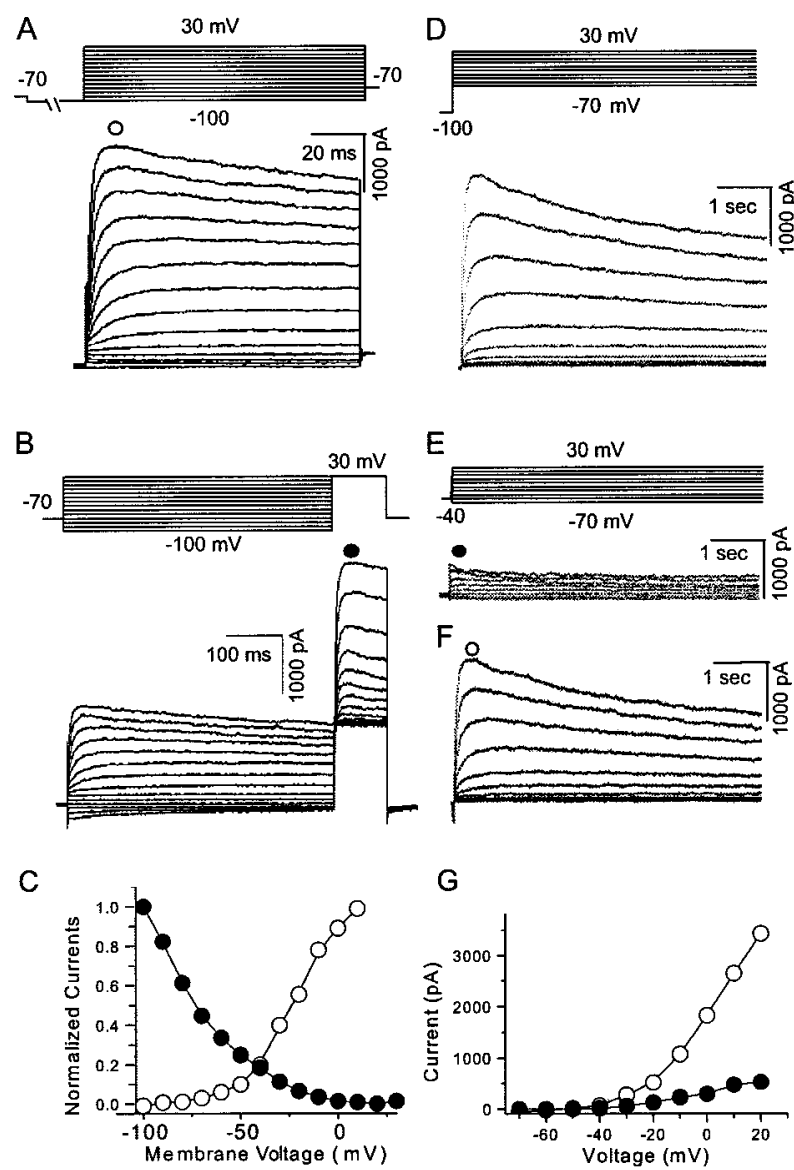

G

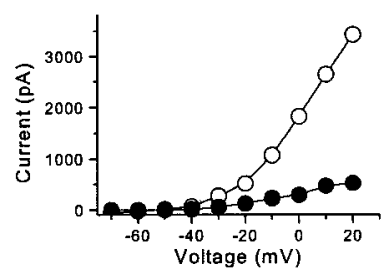

Figure 1. Whole-cell VGKCs in acutely dissociated mPFC pyramidal neurons. $A$, After holding the membrane potential at $-70 \mathrm{mV}$ and administering a 2 sec prepulse to $-100 \mathrm{mV}$, test protocols from -100 to $30 \mathrm{mV}$ with $10 \mathrm{mV}$ increments elicited the whole-cell currents $(n=16$ of 20). B, Whole-cell VGKCs could be partially inactivated by a depolarizing prepulse. After a holding potential at $-70 \mathrm{mV}$ and a $600 \mathrm{msec}$ prepulse from -100 to $30 \mathrm{mV}(10 \mathrm{mV}$ increments), 100 msec test steps to $30 \mathrm{mV}$ elicited currents showing a (pseudo) steady-state inactivation $(n=6)$. C, Current was measured at the time point indicated as an open or filled circle in $A$ and $B$. The activation and inactivation observed in $A$ and $B$ were plotted as $I-V$ curves. $D$, Whole-cell VGKC was elicited by a similar activation protocol but with longer time course ( $4 \mathrm{sec}$ ) $(n=5)$. $E$, After the holding potential at $-40 \mathrm{mV}$, the same test steps as in $D$ elicited currents showing little inactivation. This current is operationally termed $I_{K}(n=5)$. $F$, A slowly inactivating current was obtained by subtraction of traces in $E$ from $D$. This slowly inactivating component is operationally termed $I_{D}$. G, I-V curves of $I_{K}$ and $I_{D}$ indicate that both currents begin to activate at approximately $-40 \mathrm{mV}(n=5)$. Currents were measured at the time points indicated by open or filled circles in $E$ and $F$.

the kinetics of this rapidly inactivating component are similar to that of A-type currents identified previously in cortical pyramidal neurons (Foehring and Surmeier, 1993), we operationally defined it as the A-current or $I_{A}$. When $I_{A}$ is present, it contributes only to the initiation of whole-cell VGKC because it inactivates completely within the first several $10 \mathrm{msec}$. The $I-V$ curve of both early and late components measured from the same neuron is plotted in Figure $2 B$. Here, both components of the current begin to activate at $-40 \mathrm{mV}$. In general, the whole-cell VGKC in $\mathrm{mPFC}$ neurons begins to activate at $-42 \pm 3 \mathrm{mV}(n=15)$. A lack of obvious $I_{A}$ in most recorded neurons could be explained if $I_{A}$ is too small and is totally obscured by $I_{D}$. To test this hypothesis, we applied $1 \mathrm{~mm}$ TEA, which is an effective blocker of non-A-type $\mathrm{K}^{+}$current, to neurons that showed no obvious $I_{A}$ in whole-cell VGKC (Figs. 1A, 2C1). The hidden $I_{A}$ was revealed (Fig. 2C2) in this neuron after $I_{D}$ was inhibited by TEA perfusion. A similar

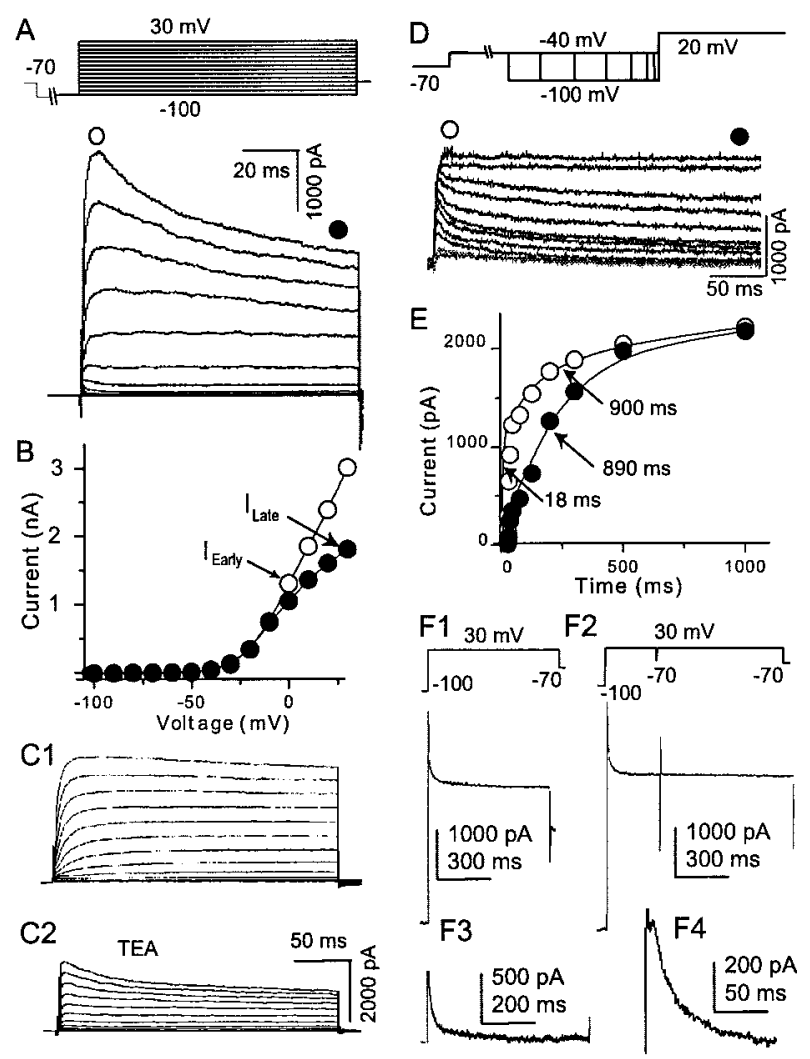

Figure 2. A-type $\mathrm{K}^{+}$component of whole-cell VGKC. $A, \mathrm{~A}$ rapid inactivating component could be observed in a small population of neurons $(n=4$ of 20$)$ using the protocol described in Figure $1 A$. The rapidly inactivating component became more obvious at more depolarized steps. Because both activation and inactivation of this component are rapid and consistent with A-type current, it is operationally called $I_{A}$. $B$, Activation curves for the early and later components are plotted with the values measured at the time points indicated by filled and open circles, respectively. $C 1$ and $(2$ show the activation of the same neuron before and after TEA perfusion, respectively. In most neurons, whole-cell VGKC activation protocols alone failed to show obvious $I_{A}$. However, after perfusion with $10 \mathrm{~mm} \mathrm{TEA}, I_{A}$ was revealed $(n=4)$. $D$, Recovery protocol shows that $I_{A}$ deinactivates more rapidly than $I_{D}$. After the holding potential at -70 $\mathrm{mV}$, a prepulse to $-40 \mathrm{mV}$ inactivated most of the VGKC. A second hyperpolarizing prepulse to $-100 \mathrm{mV}$ recovered the $\mathrm{K}^{+}$channels from the inactive state. The time course for this hyperpolarization prepulse varied from $10 \mathrm{msec}$ to $1 \mathrm{sec}$ with a nonlinear increment. $I_{A}$ could be recovered with a brief hyperpolarization step but contributes $<25 \%$ of the whole-cell current $(n=4) . E$, The recovery time and the current amplitudes (measured at the time points indicated with open and filled circles in $D)$ were plotted. The relationship of the early component $\left(I_{A}+I_{D}\right)$ could be fit with two exponentials ( $\tau_{1}=18 \mathrm{msec} ; \tau_{2}=890 \mathrm{msec}$ ). The relationship of the late component could be fit with one exponential $(\tau=900 \mathrm{msec})(n=5)$. From $F 1$ to $F 4$, I $I_{A}$ was isolated biophysically $(n=4)$. $F 1$, A neuron with obvious $I_{A}$ component was selected. By running a regular protocol, the whole-cell VGKC was elicited. This current contained $I_{A}, I_{D}$, and $I_{K}$. F2, The same testing step as in $\mathrm{F} 1$ after a $200 \mathrm{msec}$ depolarization prepulse elicited a $\mathrm{K}^{+}$trace. Because the prepulse had inactivated $I_{A}$, the following trace contained only $I_{D}$ and $I_{K}$. F3, The $I_{A}$ component was isolated after subtraction of the trace in $F 2$ from $F 2$. The trace was shown in $F 4$ in a higher magnification.

effect was observed in three other neurons. Obviously the limits of pharmacological isolation of $\mathrm{K}^{+}$currents must be noted. Low concentrations of TEA ( $1 \mathrm{mM}$ ) blocked only $\sim 50 \%$ of $I_{D}$, whereas higher concentrations ( $50 \mathrm{~mm}$ ) of TEA also blocked $I_{A}$ (see Fig. $4 A$ ).

\section{Biophysical isolation of $I_{A}$ and $I_{D}$}

To characterize further $I_{A}$ in mPFC neurons, biophysical methods were used to isolate $I_{A}$ and $I_{D}$. Deinactivation by hyperpolarization was shown by a recovery protocol in which the membrane potential was held at $-70 \mathrm{mV}$. A $4 \mathrm{sec}$ depolarization step to -40 $\mathrm{mV}$ inactivated both $I_{A}$ and $I_{D}$. The membrane potential was then 
stepped to the recovery voltage $(-100 \mathrm{mV})$ for varying durations $(5,10,20,50,100,200,500,1000 \mathrm{msec})$. A test step to $+30 \mathrm{mV}$ elicited the whole-cell VGKC (Fig. $2 D$ ). $I_{A}$ was recovered from inactivation with relatively short hyperpolarization steps and contributed only slightly to the whole-cell VGKC. Recovery of $I_{D}$ required relatively long hyperpolarization steps. After full recovery, $I_{D}$ totally obscured $I_{A}$. The currents were measured from 10 msec after onset of the current, at which $I_{A}$ reached its peak, as well as from $400 \mathrm{msec}$ after onset current, at which $I_{A}$ was completely inactivated. The relationships between these two currents and their recovery time are plotted in Figure $2 E$. The early current from this cell was well fit with two exponentials with time constants of 18 and $890 \mathrm{msec}$, respectively. The late current was well fit with one exponential with a time constant of $900 \mathrm{msec}$, consistent with the $890 \mathrm{msec}$ time constant during the early current. The averaged time constants are $39 \pm 10 \mathrm{msec}(n=5)$ and $925 \pm$ $207 \mathrm{msec}(n=5)$. Clearly, $I_{A}$ and $I_{D}$ could be distinguished by different recovery kinetics.

Another protocol was also used to isolate $I_{A}$ from whole-cell VGKC by taking advantage of the rapid inactivation of $I_{A}$ (Fig. $2 E)$. In the first part of this protocol, the test step to $+30 \mathrm{mV}$ after prolonged holding at $-100 \mathrm{mV}$ elicited whole-cell VGKC, which includes $I_{A}, I_{D}$, and $I_{K}$ (Fig. $2 F 1$ ). In the second part of this protocol, a $200 \mathrm{msec}$ prepulse to $30 \mathrm{mV}$ fully inactivated $I_{A}$ but was short enough to maintain most of $I_{D}$ and $I_{K}$ because of their slow inactivation. So the following test step from -70 to $+30 \mathrm{mV}$ elicited a current including only $I_{D}$ and $I_{K}$ (Fig. 2 F2). Subtraction of whole-cell $\mathrm{K}^{+}$current composed of $I_{D}$ and $I_{K}$ (Fig. 2 F2) from the whole-cell $\mathrm{K}^{+}$current composed of $I_{A}, I_{D}$, and $I_{K}$ (Fig. $2 \mathrm{~F} 1$ ) resulted in pure $I_{A}(n=4)$ (Figs. $\left.2 F 3,4\right)$.

We have described three components of the whole-cell VGKC, $I_{A}, I_{D}$, and $I_{K}$, in mPFC neurons, similar to that described in sensorimotor cortex pyramidal neurons (Foehring and Surmeier, 1993). Another way to distinguish different components in a combined current is to analyze current decay (Hoshi et al., 1990). An outward current trace was elicited by a $200 \mathrm{msec}$ step to $+30 \mathrm{mV}$ from a holding potential of $-100 \mathrm{mV}$ (Fig. $3 A$, inset). The point at which VGKC starts to decay is defined at $10 \mathrm{msec}$ after the onset of peak current. The digitized current was taken from the $10 \mathrm{msec}$ point to total decay. Using this protocol, the decay could be fit by two exponentials with time constants $(\tau)$ of 15 and $250 \mathrm{msec}$. The two components became more obvious when the current was converted to logarithmic values (Fig. $3 A$ ). The late current was extrapolated and subtracted from the early current. The VGKC was peeled into two linear exponentials in the logarithmic coordinates (Fig. 3A). Another protocol with similar activation steps but longer duration $(4 \mathrm{sec})$ was used to generate the decay current (Fig. 3B, inset). The decay was analyzed with a similar peeling process, and two decay time constants were obtained (200 msec and $2.9 \mathrm{sec}$ ). No faster $\tau$ could be obtained because the step duration is too long to catch short inactivating $(\tau=15 \mathrm{msec})$ components. The fast $\tau(200 \mathrm{msec})$ in Figure $3 B$ is consistent with the slow $\tau(250 \mathrm{msec})$ in Figure $3 A$, which suggests that they are the same component. The less than perfect consistency may be attributable to the heterogeneous expression of VGKC but is more likely the result of different time courses used to truncate the current. In Figure 3B, the decay of the 250 msec component occupies the entire time course of the analysis and should be more accurate.

Another similar protocol but with a much longer step (40 sec) generated a VGKC trace that was well fit with two exponentials $(\tau=3.4$ and $25 \mathrm{sec}$, respectively). Again the $3.4 \sec \tau$ in Figure $3 C$ is consistent with the $2.9 \mathrm{sec} \tau$ in Figure 3B. Taken together, there
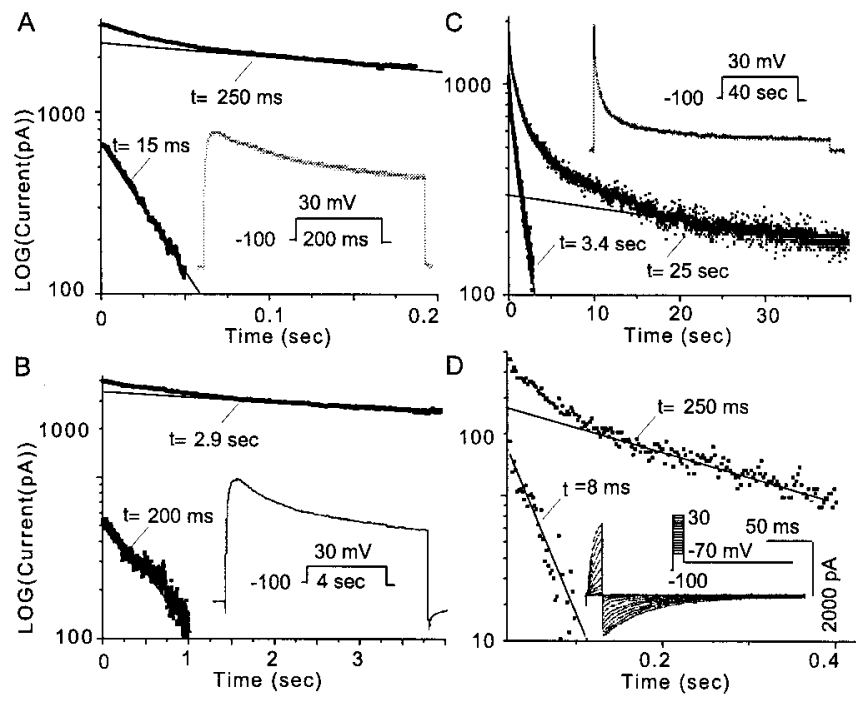

Figure 3. Multiple components of whole-cell VGKC revealed by inactivation kinetics. A, A cell with obvious $I_{A}$ was selected for this example. Whole-cell VGKC was elicited during a $200 \mathrm{msec}$ step to $30 \mathrm{mV}$ from $-100 \mathrm{mV}$, as shown in the inset. The current amplitude was digitized and put in a LOG coordinate. The late part, but not the early part, of the current displayed a linear relationship with a time constant of $250 \mathrm{msec}$. This linear relationship was then extrapolated forward and subtracted from the early part of the digitized current, which resulted in another linear relationship with a time constant of $15 \mathrm{msec}$. This exponential peeling of decay within the time course demonstrated two components $(n=7)$. B, Whole-cell VGKC was elicited during a longer ( $4 \mathrm{sec}$ ) step to $30 \mathrm{mV}$ from $-100 \mathrm{mV}$, as shown in the inset. Exponential peeling of the components of decay of this trace revealed two time constants of $200 \mathrm{msec}$ and $2.9 \mathrm{sec}(n=6)$. C, Whole-cell VGKC was elicited during a 40 sec step to $30 \mathrm{mV}$ from $-100 \mathrm{mV}$, as shown in the inset. Exponential peeling of the components of decay of this trace revealed two time constants of 3.4 and $25 \mathrm{sec}(n=3)$. D, A protocol as shown in the inset was used to elicit the $\mathrm{K}^{+}$tail current. Exponential fitting revealed two components in the tail current (using the $40 \mathrm{mV}$ step as the example) with time constants of 8 and $43 \mathrm{msec}(n=4)$. Taken together, these data support four distinct inactivation time constants, one consistent with $I_{A}$, one consistent with $I_{{ }^{\prime}}$ and two as distinct components of $I_{D}$.

are four components according to the time constants of current decay: $12 \pm 3 \mathrm{msec}(n=7), 220 \pm 26 \mathrm{msec}(n=6), 3.4 \pm 0.5 \mathrm{sec}$ $(n=6)$, and $33 \pm 7 \sec (n=3)$. The strategy to isolate these four time constants is to progressively increase the voltage step duration. When the step was much longer than a time constant, the component to this $\tau$ decayed too quickly to be taken into account in such a long step. On the contrary, the decay of the component with matched $\tau$ that predominated in this analysis can be calculated accurately. The rapidly inactivating (12 $\pm 3 \mathrm{msec})$ component is consistent with $I_{A}$. The very slowly inactivating (33 \pm 7 sec) component is consistent with $I_{K}$. We propose that there are two components in $I_{D}$, with decay $\tau$ of $220 \pm 26 \mathrm{msec}$ and $3.4 \pm$ $0.5 \mathrm{sec}$, respectively. The pseudo-steady-state inactivation data (see Fig. 5D) indicate the likelihood that there are at least two components in $I_{D}$, consistent with our hypothesis.

We next examined current decay with a tail current protocol (Fig. 3D). This experiment was performed in $40 \mathrm{~mm}$ external $\mathrm{K}^{+}$ and $\mathrm{Cl}^{-}$was replaced with methanesulfonate. The membrane potential was held at $-100 \mathrm{mV}$. The tail currents were elicited by stepping to $-70 \mathrm{mV}$ after $10 \mathrm{msec}$ voltage commands to steps from -60 to $+30 \mathrm{mV}$ with $10 \mathrm{mV}$ increments. In cells with $I_{A}$, the tail current was well fit by two exponentials with time constants of 8 and $43 \mathrm{msec}$ (Fig. 3D). Similar $2-\tau$ deactivation was also observed in three other neurons (4 and $19 \mathrm{msec} ; 9$ and $28 \mathrm{msec} 7$ and $33 \mathrm{msec}$ ), suggesting that there are at least two components involved in the tail current. Note that it is difficult to correlate the deactivation $\tau$ values with inactivation $\tau$ values. 
Pharmacological isolation of $\mathrm{K}^{+}$currents

The biophysical studies above suggest that mPFC pyramidal neurons express at least four components of the whole-cell VGKC. Are they attributable to different channels or to similar channels with different gating properties? The following pharmacological studies attempted to address this question.

Three pharmacological agents, TEA, 4-AP, and DTX, were applied to $I_{D}$ and $I_{K}$ currents. $I_{K}$ was elicited by a $100 \mathrm{msec}$ step to $+10 \mathrm{mV}$ from a holding potential of $-40 \mathrm{mV}$ (Fig. 4A2,B2,C2). A whole-cell VGKC was elicited by a similar protocol except that the prepulse was $-100 \mathrm{mV} . I_{D}$ was generated by subtraction of $I_{K}$ from this whole-cell current (Fig. 4A1,B1,C1).

$I_{A}$ was TEA insensitive (Fig. 2C2), but $I_{K}$ and $I_{D}$ were reversibly blocked by TEA across a broad concentration range (Fig. $4 A 3, A 4)$. The relationship between relative current $\left(I / I_{\max }\right)$ of $I_{K}$ and LOG[TEA] was well fit with a two-site model (Langmuir isotherm) with $\mathrm{IC}_{50}$ values of $8 \mu \mathrm{M}$ and $4 \mathrm{~mm}$ (Fig. 4A3). The dose-response curve for $I_{D}$ was also well fit with a twosite model with $\mathrm{IC}_{50}$ values of $25 \mu \mathrm{M}$ and $10 \mathrm{~mm}$ (Fig. 4A4). $I_{A}$ in mPFC pyramidal neurons was sensitive to 4-AP and blocked by $60 \%$ at low (1-5 mM) concentrations (data not shown). Both $I_{K}$ and $I_{D}$ currents were also sensitive to 4-AP in our study (Fig. 4B3,B4). The relationship between relative current and LOG [4-AP] for $I_{K}$ was well fit with a two-site model with $\mathrm{IC}_{50}$ values of $60 \mu \mathrm{M}$ and $6 \mathrm{~mm}$ (Fig. $4 \mathrm{B3}$ ). The effects of 4 -AP on $I_{D}$ currents are relatively limited. The maximal blockade was $\sim 35 \%$ when $10 \mathrm{~mm} 4$-AP was applied. The dose-response curve was well fit with a single-site model with an $\mathrm{IC}_{50}$ of $30 \mu \mathrm{M}$ (Fig. $4 B 4) . I_{A}$ was insensitive to low $(1-10 \mathrm{nM})$ concentrations of DTX, but both $I_{D}$ and $I_{K}$ were blocked by DTX across a broad concentration range. The dose-response curve for $I_{K}$ was best fit with a two-site model with $\mathrm{IC}_{50}$ values of $800 \mathrm{pm}$ and $52 \mathrm{~nm}$ (Fig. 4C3). The does-response curve for $I_{D}$ was well fit with a two-site model with $\mathrm{IC}_{50}$ values of $200 \mathrm{pm}$ and $40 \mathrm{~nm}$ (Fig. 4C4). The two $\mathrm{IC}_{50}$ values usually suggest two binding sites in the channels or two kinds of channels. The similar pharmacology of VGKC (multiple binding sites or multiple channels) was reported previously in sensorimotor cortical neurons (Foehring and Surmeier, 1993).

\section{DA modulation of VGKC}

The whole-cell VGKC is composed of three components, $I_{A}, I_{D}$, and $I_{K}$, each of which display different biophysical and pharmacological properties. In this section of the study, we examined DA receptor modulation of each VGKC component. In this set of simplified protocols, $I_{K}$ was elicited when the membrane potential was stepped to $+30 \mathrm{mV}(2 \mathrm{sec})$ from prolonged $(>10 \mathrm{sec})$ holding at $-40 \mathrm{mV}$ (Fig. 5A). The current amplitude was measured at the time point $200 \mathrm{msec}$ after current initiation. To elicit $I_{D}$, the membrane potential was held at $-100 \mathrm{mV}$. The prepulse $(100 \mathrm{msec})$ to $+30 \mathrm{mV}$ was used to inactivate available $I_{A}$. After a brief hyperpolarization ( $1 \mathrm{msec}$ ) to $-70 \mathrm{mV}$, the membrane potential was again stepped to $+30 \mathrm{mV}$, which elicited the com- bined current of $I_{D}$ and $I_{K}$ (Fig. $5 B$ ). Because $I_{K}$ is so small compared with $I_{D}$, and because $I_{K}$ is insensitive to D1R stimulation (see below), the combined current is regarded as $I_{D}$ in the following functional studies. The current amplitude was measured at the time point $100 \mathrm{msec}$ after onset. The detailed isolation of $I_{A}$ was described in Figure $2 F$. Peak $I_{A}$ was measured and was regarded as $I_{A}$ amplitude. The relative current, or $I_{\text {Relative }}$, is defined as current amplitude during perfusion of drug divided by current amplitude in control $\left(I_{\text {Perfusion }} / I_{\text {Control }}\right)$.

$I_{K}$ was insensitive to D1R stimulation. Activation of D1Rs with the selective agonist SKF $81297(0.1$ and $1 \mu \mathrm{M})$ failed to induce any change in current amplitude of $I_{K}(n=5$ for each concentration) (Fig. 5A,E). However, in the same neuron, SKF 81297 induced a significant inhibition of $I_{D}$ amplitude (Fig. $5 B$ ). The D1R-mediated inhibition of $I_{D}$ was dose dependent. Perfusion of neurons with $0.1 \mu \mathrm{M}$ SKF 81297 induced $19 \pm 3 \%$ inhibition of $I_{D}$ amplitude $(n=15 ; p<0.05$; paired $t$ test between control and perfusion of SKF 81297,) whereas perfusion with $1 \mu \mathrm{M}$ SKF 81297 induced $34 \pm 5 \%$ inhibition of $I_{D}$ amplitude $(n=10 ; p<0.05$; paired $t$ test between control and perfusion of SKF 81297) (Fig. $5 B, E$ ). The D1R-mediated inhibition (by SKF 81297, $0.1 \mu \mathrm{M}$ ) was reversible after wash and was antagonized by the DA D1Rselective antagonist SCH $23390\left(1 \mu \mathrm{M} ; n=5 ; I_{\text {Relative }}=0.98 \pm\right.$ 0.02 ) (Fig. $5 B, E$ ). In most neurons ( 6 of 7 ), $I_{D}$ was also inhibited by the partial DA D1R agonist SKF38393 (0.1 $\mu \mathrm{M}$; data not shown). In another neuron, whole-cell VGKC was elicited by a voltage step $(1 \mathrm{sec})$ to $+30 \mathrm{mV}$ from a holding potential of -100 $\mathrm{mV}$ (Fig. 5C, inset). An obvious inhibition in the late component $\left(I_{D}\right)$ of VGKC could be observed when the neuron was perfused with SKF $81297(0.1$ and $1 \mu \mathrm{M})$ (Fig. 5C, inset). $I_{A}$ from this 


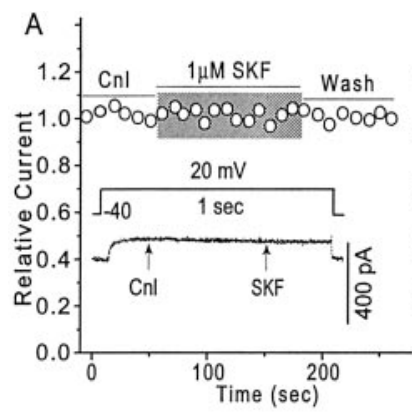

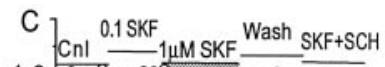
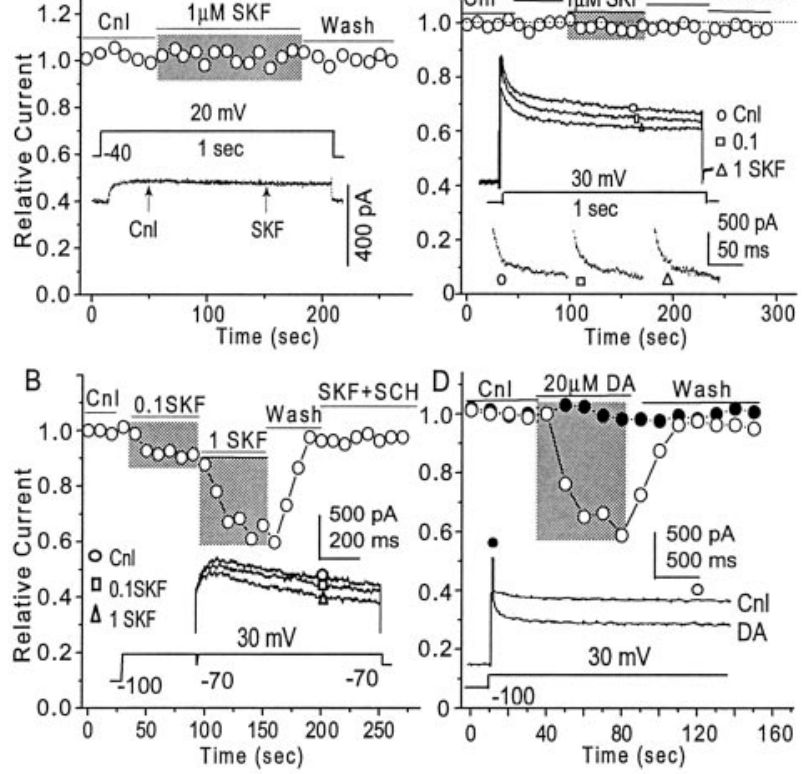

E

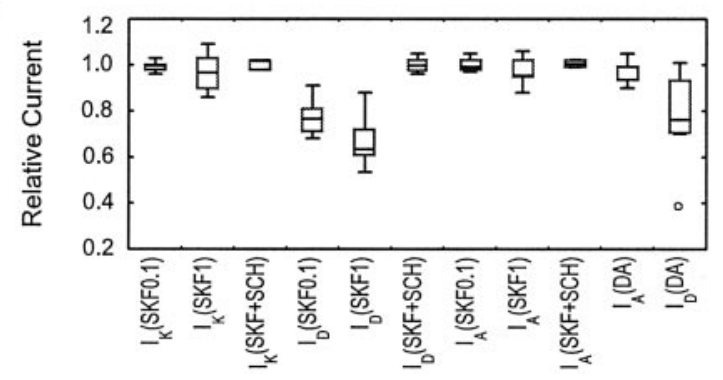

Figure 5. Dopamine D1 receptor-mediated inhibition of VGKC. A, Activation of D1 receptors by the selective agonist SKF $81297(0.1$ and $1 \mu \mathrm{m})$ failed to alter $I_{K}(n=5)$. The inset shows two traces of $I_{K}$ in the presence and absence of SKF $81297(0.1 \mu \mathrm{M})$, clearly indicating the lack of effect of D1 receptor stimulation on this current. B, Activation of D1 receptors with SKF 81297 produced a dose-dependent suppression of $I_{D}(n=25)$, which was prevented by the D1 receptor antagonist SCH 23390 ( $n=5$ ). Inset traces clearly show the dose-dependent modulation. $C$, Activation of D1 receptors by SKF $81297(1 \mu \mathrm{M})$ failed to alter $I_{A}(n=5)$. Inset traces show the overall effect of SKF 81297 and the effect on the isolated $I_{A}$. D. The late component of VGKC (mostly $I_{D}$ ) was measured at the open circle in inset; peak VGKC (mostly $I_{A}$ ) was measured at the beginning of the current, as indicated by the filled circle in inset. Perfusion of DA (20 $\mu \mathrm{m})$ failed to alter peak VGKC (mostly $\left.I_{A}\right)(n=5$; filled circles) but significantly inhibited the late component of VGKC (mostly $\left.I_{D}\right)(n=6$; open circles). $E$, The effects of DA and SKF 81297 on the various components of VGKC are summarized in a box-whisker plot. Concentrations of $0.1 \mu \mathrm{M}$ SKF $81297(n=5), 1 \mu \mathrm{M}$ SKF 81297 ( $n=5)$, or $0.1 \mu \mathrm{M}$ SKF 81297 with $1 \mu \mathrm{MSCH} 23390(n=3)$ failed to alter the amplitude of $I_{K}$. Perfusion of $0.1 \mu \mathrm{m}$ SKF 81297 produces a $19 \pm 3 \%$ inhibition of $I_{D}(n=15)$. Perfusion of $1 \mu \mathrm{M}$ SKF 81297 produces a $34 \pm 17 \%$ inhibition of $I_{D}(n=10)$. Perfusion of $0.1 \mu \mathrm{M}$ SKF 81297 together with $1 \mu \mathrm{M} S C H 23390$ does not alter the amplitude of $I_{D}$ $\left(I_{\text {Relative }}=0.96 \pm 0.03 ; n=5\right)$. Perfusion of $0.1(n=3)$ or $1 \mu \mathrm{M}$ SKF $81297(n=5)$, or SKF $81297(0.1 \mu \mathrm{M})$ with SCH $23390(1 \mu \mathrm{M})(n=3)$, does not alter the amplitude of $I_{A}$. Perfusion of DA does not alter $I_{A}\left(I_{\text {Relative }}=0.93 \pm 0.09 ; n=5\right)$ but inhibits $I_{D}\left(I_{\text {Relative }}=0.78 \pm 0.06 ; n=6\right.$.).

neuron was isolated from each perfusion condition (Fig. 5C, inset), displaying no response to D1R stimulation (Fig. $5 C$ ). In most neurons, no alteration in $I_{A}$ amplitude was observed when D1Rs were stimulated by SKF 81297 at concentrations of $0.1 \mu \mathrm{M}$ $\left(I_{\text {Relative }}=1.03 \pm 0.04 ; n=5\right.$, $)$ or $1 \mu \mathrm{M}\left(I_{\text {Relative }}=0.95 \pm 0.05 ; n=\right.$ 5,) (Fig. 5C,E).

No obvious alterations in whole-cell VGKC (or either component of VGKC) were observed when D2Rs were stimulated by the selective D2R agonist quinpirole $(0.1$ and $1 \mu \mathrm{M} ; n=9$; data not shown). We next examined how DA, the endogenous agonist,

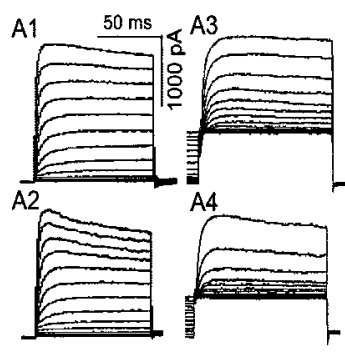

B

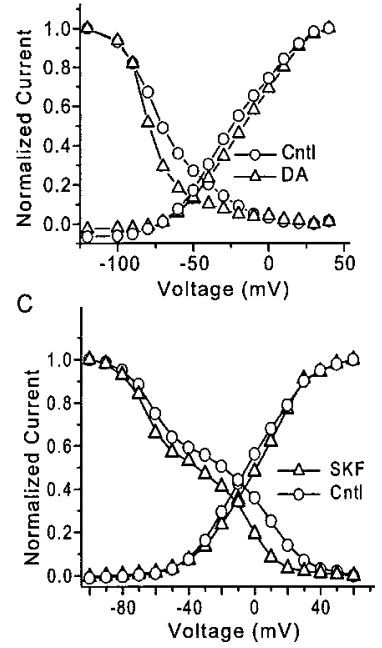

Figure 6. The effects of dopamine (DA) and SKF 81297 on the VGKCI-V relationship. $A 1, A 2$, The activation protocol (as in Fig. $1 A$ ) elicited VGKC before and during perfusion of DA $(20 \mu \mathrm{M})$. $A 3, A 4$, The inactivation protocol (as in Fig. 1B) elicited VGKC in the same pyramidal mPFC neuron before and during perfusion of $20 \mu \mathrm{m} \mathrm{DA}$. B, The I-V curve for whole-cell VGKC from the neuron shown in $A$ is plotted. DA clearly produces a hyperpolarizing shift in the inactivation curve of VGKC in mPFC neurons ( $n=3$ of 3). C, A similar shift of the inactivation curve was observed during perfusion of the D1 receptor agonist SKF $81297(0.1 \mu \mathrm{M})$. The inactivation of these neurons could be best fit with two Boltzmann equations, suggesting that two components with distinct inactivation kinetics are involved in the whole-cell VGKC.

affects VGKC. Whole-cell VGKC was elicited when the membrane potential was stepped to $+30 \mathrm{mV}$ (4 sec) from a holding potential of $-100 \mathrm{mV}$. In the neuron shown in Figure $5 D$, inset, the very rapid inactivating component $\left(I_{A}\right)$ was observed. The amplitude of the peak current (mostly $I_{A}$ ) was measured at the time point $10 \mathrm{msec}$, as indicated by the filled circle. The amplitude of the late component (mostly $I_{D}$ ) was measured at the time point $3 \mathrm{sec}$, as indicated by the open circle in Figure $5 D$, inset. Perfusion of neurons with DA $(20 \mu \mathrm{M})$ did not alter peak VGKC $\left(\right.$ mostly $\left.I_{A}\right)\left(I_{\text {Relative }}=0.93 \pm 0.05 ; n=5\right)$, but induced a washable inhibition of the late component (mostly $\left.I_{D}\right)\left(I_{\text {Relative }}=\right.$ $0.78 \pm 0.06 ; n=6$ ) (Fig. $5 D, E)$. A summary of DA-induced inhibition of VGKC (Fig. $5 E$ ) indicates that (1) activation of D1R does not affect $I_{K}$ and $I_{A}$ but reliably inhibits $I_{D}$, and (2) DA inhibits VGKC via its action on D1Rs.

We next examined the effects of DA on the $I-V$ curve of whole-cell VGKC, which could be obtained by the protocols described in Figure 1C. DA-induced (30 sec perfusion) inhibition of current amplitude could be observed in both activation traces and pseudo-inactivation traces (Fig. 6A). DA did not alter activation but shifted inactivation in the hyperpolarizing direction (Fig. $6 B)$ [half-inactivation voltage $\left(V_{\mathrm{h}}\right)$ of VGKC shifted $5.4 \pm$ $1.2 \mathrm{mV}$ in the hyperpolarizing direction by DA; $n=3$ ]. We argued above that DA modulates VGKC via its action on D1Rs, so it was not surprising that stimulation of D1Rs by SKF 81297 
induced a similar left-shift of inactivation in VGKC, but activation remained intact (Fig. 6C). It could also be observed that two components (two Boltzmann equations) were involved in the inactivation, which was interpreted as two components in the earlier section of this study. It is worth mentioning that the variability of $V_{\mathrm{h}}$ among neurons is high in our preparations, which may be attributable to the diverse expression of $\mathrm{K}^{+}$channels/currents, the inadequate voltage clamp, the incomplete compensation of junction potential, or other factors. However, in all recorded neurons the $V_{\mathrm{h}}$ consistently exhibited a left-shift $\left(\Delta V_{\mathrm{h}}=5.3 \pm\right.$ $1.1 \mathrm{mV} ; n=6)$ in responding to $\mathrm{D} 1 \mathrm{R}$ activation, suggesting that $\mathrm{D} 1 \mathrm{R}$ suppression of VGKC might be mediated by the enhanced inactivation of $\mathrm{K}^{+}$channels.

\section{Mechanisms responsible for D1R modulation of $\boldsymbol{I}_{D}$}

D1Rs are positively coupled to the adenylyl cyclase/cAMP/protein kinase A (PKA) signal transduction pathway (Stoof and Kebabian, 1984). By activation of this pathway, D1Rs have been shown to suppress whole-cell $\mathrm{Na}^{+}$current in ventral and dorsal striatal medium spiny neurons (Surmeier et al., 1992; Zhang et al., 1998), PFC pyramidal neurons (Maurice et al., 2001), and hippocampal pyramidal neurons (Cantrell et al., 1997, 1999). To determine whether this signal transduction pathway is also responsible for the D1R modulation of VGKC, we stimulated or inhibited each component of this signal cascade and examined the role of this pathway in D1R-mediated modulation of VGKC.

Perfusion of $20 \mu \mathrm{M} 8$-Br-Sp-cAMP, a membrane-permeable cAMP analog with strong PKA activating effect, induced a significant inhibition of the late component of whole-cell VGKC (mostly $I_{D}$ ) but did not suppress the fast-inactivating component (mostly $I_{A}$ ) (Fig. 7A). Whole-cell VGKC amplitude (measured at the end of the traces) was decreased by $26 \pm 6 \%(n=5 ; p<0.05$; paired $t$ test between control and perfusion of cAMP) (Fig. $7 A, F)$. Perfusion of $10 \mu \mathrm{M}$ forskolin, a membrane-permeable activator of AC, inhibited VGKC by $22 \pm 4 \%(n=6)$, whereas incubation with $\mathrm{H} 8(10 \mu \mathrm{M})$, the nonspecific PKA inhibitor, enhanced VGKC by $21 \pm 5 \%(n=5)$ (Fig. $7 B, F)$. Basal VGKC could also be enhanced by PKI, a more specific PKA inhibitor $(n=2$; data not shown). OA was used to examine whether the $\mathrm{K}^{+}$channel is the direct substrate of PKA. OA is a strong inhibitor of multiple phosphatases, inhibition of which blocks dephosphorylation of VGKC channels, resulting in more phosphorylated channels. Perfusion of $100 \mathrm{~nm}$ OA suppressed VGKC (17 $\pm 4 \%$; $n=4$ ) (Fig. $7 C, F)$. The OA-induced inhibition of VGKC could not be washed out because of its irreversible binding to phosphatases. The above experiments suggest that (1) sequential activation of adenylyl cyclase, cAMP, and PKA is sufficient for VGKC inhibition, (2) constitutive activity of PKA tonically inhibits VGKC, and (3) $\mathrm{K}^{+}$ channels underlying VGKC exist in a dynamic balance between phosphorylation and dephosphorylation states and can be modulated in either direction.

Other signal transduction cascades are also reported to participate in D1R signaling (Undie et al., 2000). Is the AC/cAMP/PKA pathway also necessary in mediating D1R effects on VGKC? The next two experiments addressed this question. The pipette solution contained $1 \mathrm{U} / \mathrm{ml}$ PKI subunit, a PKA inhibitor. After cell rupture, PKI diffused into the neuron, blocking PKA-mediated phosphorylation. After full blockade of PKI was obtained (monitored as the amplitude of VGKC became stable), perfusion with SKF 81297 no longer reduced VGKC $\left(I_{\text {Relative }}=1.04 \pm 0.05 ; n=\right.$ 4) (Fig. $7 D, F)$. Similar experiments were performed with another PKA inhibitor, Rp-cAMP, the nonfunctional cAMP analog that neutralizes intracellular cAMP activity so that PKA activity is
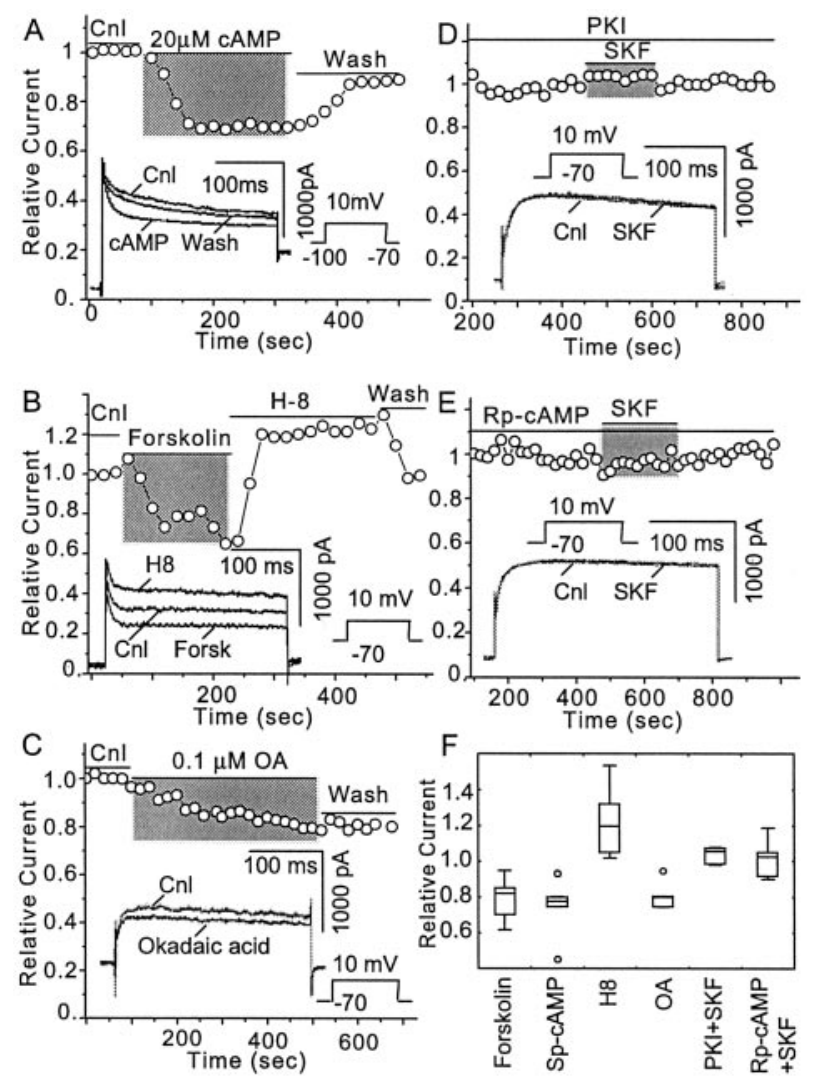

Figure 7. The adenylyl cyclase/cAMP/protein kinase A (PKA) signaling system mediates DA D1 receptor inhibition of $I_{D}$. $A$, Sp-CAMP $(20 \mu \mathrm{M})$, a membrane-permeable CAMP analog that activates protein kinase $A$ directly, inhibited $I_{D}(n=6)$ but not $I_{A}$. $B$, Forskolin $(10 \mu \mathrm{m})$, a membrane-permeable stimulator of adenylyl cyclase, also inhibited $I_{D}(n=6)$. Perfusion of the same neuron with $\mathrm{H} 8(10 \mu \mathrm{M})$, a membrane-permeable PKA inhibitor, increased $I_{D}(n=5)$. $C$, The membrane-permeable protein phosphatase inhibitor okadaic acid (100 nm) inhibited $I_{D}$ $(n=4)$. D, The PKI subunit $(1 \mathrm{U} / \mathrm{ml})$ was included in the pipette solution and diffused into the cell when the whole-cell configuration was formed. Once the CAMP/PKA pathway was fully blocked by PKI, indicated as the VGKC reached steady state, the inhibitory effect of SKF 81297 (1 $\mu \mathrm{m})$ was also blocked $(n=4)$. E, Perfusion of Rp-CAMP $(50 \mu \mathrm{M})$, a membrane-permeable cAMP analog with strong inhibitory effects on PKA $(n=5)$, also blocked the inhibition by SKF 81297 $(1 \mu \mathrm{M})$. F, This plot summarizes the contribution of each component of the AC/CAMP/PKA pathway to D1R-mediated modulation of VGKC. Perfusion of Sp-Br-cAMP suppresses VGKC by $26 \pm 6 \%(n=5)$. Perfusion of forskolin suppresses VGKC by $22 \pm 4 \%(n=6)$, whereas perfusion of 8 enhances VGKC by $21 \pm 5 \%$. Perfusion of okadaic acid suppresses VGKC by $17 \pm$ $4 \%(n=4)$. VGKCs become resistant to the stimulation of D1R when the cell is treated with either PKI $\left(I_{\text {Relative }}=1.04 \pm 0.05 ; n=4\right)$ or Rp-CAMP $\left(I_{\text {Relative }}=1.02 \pm 0.05 ; n=5\right)$.

blocked. Perfusion of Rp-cAMP (50 $\mu \mathrm{M})$ initially induced an enhancement of VGKC (data not shown). After the PKA is fully inactivated, which was indicated as VGKC became stable, SFK 81297 failed to suppress VGKC $\left(I_{\text {Relative }}=1.02 \pm 0.05 ; n=5\right)$ (Fig. $7 E, F$ ). In sum, the above results suggest that the AC/cAMP/ PKA pathway is essential to D1R modulation of VGKC.

\section{Discussion}

The effects of DA on mPFC pyramidal neurons have remained an enigma for $>25$ years (for review, see Yang et al., 1999). Although recent studies have begun to elucidate the means by which DA modulates neuronal excitability in subcortical areas (for review, see Nicola et al., 2000), such clarification has been slower to emerge in the mPFC, perhaps because previous in vivo and in vitro characterizations have been even more controversial than long-standing disputes regarding striatal neurons. Our wholecell voltage-clamp studies provide the first direct demonstration 
of DA receptor modulation of isolated VGKCs in pyramidal neurons of the mPFC. Although this technical approach has the disadvantages of a lack of neuronal processes as a result of the dissociation process and a potential disruption of cytosolic messenger systems, it provides excellent voltage control and easy access to pharmacological agents, thereby allowing isolation of whole-cell VGKC and the ability to examine the effects of DA on individual components of VGKC. Our results clearly show that DA D1Rs, but not D2Rs, selectively decrease a slowly inactivating $\mathrm{K}^{+}$conductance via the classical D1R/AC/cAMP/PKA signaling pathway.

\section{Biophysical and pharmacological dissection of VGKCs}

We identified at least three major contributors to whole-cell $\mathrm{K}^{+}$ current in mPFC pyramidal neurons, $I_{A}, I_{D}$, and $I_{K}$, as indicated by both biophysical and pharmacological dissection. These findings are consistent with previously described $\mathrm{K}^{+}$currents in sensorimotor cortical neurons (Foehring and Surmeier, 1993). Although four time constants were obtained from studies of current decay, it is difficult to know whether three or more types of $\mathrm{K}^{+}$ channels are responsible for these components as revealed by different biophysical properties. Multiple $\mathrm{K}^{+}$channels can express homogeneous biophysics (Coetzee et al., 1999), and identical channels can express heterogeneous biophysics, as a result of post-translational modification and interactions with auxiliary subunits (Heinemann et al., 1996; Holmqvist et al., 2001). Here we focused on current type as opposed to distinct channel proteins.

The fast decaying component of the whole-cell VGKC $(\tau=$ $12 \pm 3 \mathrm{msec}$ ) is kinetically consistent with the fast inactivating component $I_{\mathrm{A}}$, whereas the very slow decay component $(\tau=$ $33 \pm 7 \mathrm{sec}$ ) is kinetically consistent with $I_{\mathrm{K}}$. The other two components $(\tau=220 \pm 26 \mathrm{msec}$ and $3.4 \pm 0.5 \mathrm{sec})$ are consistent with the slowly inactivating component $I_{\mathrm{D}}$. Although the two components of $I_{\mathrm{D}}$ could not be isolated with activation protocols (Fig. 1), they were dissociable during inactivation in some neurons (Fig. 5D). This conclusion is consistent with recent findings in pyramidal neurons from several cortical regions, for example, in young neocortical neurons (Korngreen and Sakmann, 2000; Bekkers and Delaney, 2001), visual cortical neurons (Locke and Nerbonne, 1997), neocortex layer I neurons (Zhou and Hablitz, 1996), and sensorimotor cortical neurons (Foehring and Surmeier, 1993).

In dissociated mPFC neurons, $I_{\mathrm{A}}$ was often too small to be detected. Similar results were observed in acutely dissociated sensorimotor cortical pyramidal neurons (Foehring and Surmeier, 1993), cultured hippocampal pyramidal neurons (Murakoshi and Trimmer, 1999), or dissociated striatal spiny neurons (Surmeier et al., 1991), but in dissociated rat hippocampal neurons, A-current was shown to prevail, and it contributed $61 \%$ of total $\mathrm{K}^{+}$currents (Martina et al., 1998). The difference in expression of A-currents could be interpreted as cellular diversity between hippocampal and mPFC pyramidal neurons. An alternative interpretation is developmental regulation. Sensorimotor, striatal, and mPFC neurons that exhibited small A-current were dissociated from mature animals ( 4 weeks or older), whereas hippocampal neurons that displayed predominant A-current were obtained from young rats (11-16 d) (Martina et al., 1998). Both cultured and premature neonatal striatal neurons exhibit large A-currents, whereas in mature striatal neurons, the A-current is much less prominent (Surmeier et al., 1991). Thus, different developmental ages could be responsible for expression of different channel proteins.
Pharmacological studies confirm our biophysical findings of multiple currents involved in the whole-cell VGKC. $I_{K}$ displayed two $\mathrm{IC}_{50}$ values for all three blockers (4-AP, TEA, and DTX) that we used. $I_{D}$ also displayed two $\mathrm{IC}_{50}$ values for TEA and DTX. This suggests that both $I_{D}$ and $I_{K}$ contain at least two types of currents. $I_{D}$ displayed only one $\mathrm{IC}_{50}$ for 4 -AP, but the maximum blockade by 4 -AP is only $\sim 50 \%$, indicating that there is at least one component of $I_{D}$ that is 4-AP insensitive. In principle, the two types of currents, identified by the two $\mathrm{IC}_{50}$ values, likely result from two distinct types of channels, but this prediction only works well in homogenous expression systems and may not hold in electrophysiological studies of native neurons, in which two different $\mathrm{IC}_{50}$ values are not sufficient to conclude that there are two different channel types (Kirsch and Drewe, 1993). The inactivation analysis shows that there are two components (two $\tau$ values) in $I_{D}$, which is consistent with the pharmacological results (two $\mathrm{IC}_{50}$ values). There is no direct biophysical evidence indicating the composition (two components) of $I_{K}$, but the pharmacological data show two components (two $\mathrm{IC}_{50}$ values). This could indicate that $I_{K}$ contains two components that share similar biophysical properties but differ in binding to pharmacological agents. However, because the decay time constant of the slow component in $I_{D}$ is relatively large $(3.4 \mathrm{sec})$, in the protocol that we used to isolate $I_{K}$, prolonged holding $(10-20 \mathrm{sec})$ at $-40 \mathrm{mV}$ may not totally inactivate $I_{D}$, resulting in contamination of $I_{K}$. Therefore, the alternative interpretation is that the uninactivated slow component of $I_{D}$ may contribute to one of the $\mathrm{IC}_{50}$ values of $I_{K}$. Both biophysical (two $\tau$ values) and pharmacological (two $\mathrm{IC}_{50}$ values) analyses argue that there are two components in $I_{D}$, so in theory the correlation of the $\tau$ values with the $\mathrm{IC}_{50}$ values could be obtained by totally blocking the component with small $\mathrm{IC}_{50}$ (with low concentration) and calculating the $\tau$ of the rest of the current. However, technical limitations prevented us from resolving this question. In a small number of our experiments, low concentrations of the blockers never "totally" blocked the one component, and when we increased concentrations, the other component was also considerably affected.

\section{Dopamine modulation of VGKC}

The mesocortical DA input arises from the VTA and predominately terminates on pyramidal neurons in deep layers of $\mathrm{mPFC}$ (Bjorklund et al., 1978; Emson and Koob, 1978; Berger et al., 1991; Carr et al., 1999). Both D1Rs and D2Rs are expressed in pyramidal neurons, although the density of D2R appears to be considerably lower (Gaspar et al., 1995; Vincent et al., 1995). It is widely accepted that D1Rs positively couple to the AC/cAMP/ PKA signal transduction pathway, whereas D2Rs inhibit this transduction system (Stoof and Kebabian, 1984; Sibley and Monsma, 1992). Thus, we expected VGKC to be modulated in opposite ways by D1Rs and D2Rs. Surprisingly, most recorded neurons did not respond to D2R agonists. Does this indicate a lack of D2R expression in mPFC pyramidal neurons? Apparently not, because our parallel studies demonstrate that when inwardly rectifying $\mathrm{K}^{+}$current (IRKC) and VGKC were sequentially elicited in the same mPFC neuron, D2R agonists modulate only IRKC but do not affect VGKC (Dong and White, 2001), suggesting selective targeting of specific $\mathrm{K}^{+}$channels for D2R activation.

D1R activation suppresses only $I_{\mathrm{D}}$ in $\mathrm{mPFC}$ neurons, suggesting that the channel(s) conducting $I_{\mathrm{D}}$ is selectively targeted by D1Rs as opposed to channels conducting $I_{\mathrm{A}}$ and $I_{\mathrm{K}}$. A similar inhibition of VGKC induced by PKA activation was observed in the soma of striatal medium spiny neurons (Surmeier and Kitai, 1993) as well as in dendrites of hippocampal pyramidal neurons 
(Hoffman and Johnston, 1999). Delayed rectifier $\mathrm{K}^{+}$current $\left(I_{\mathrm{K}}\right)$, as well as the late component of $I_{\mathrm{D}}$, is primarily responsible for action potential duration, whereas transient $\mathrm{K}^{+}$currents, $I_{\mathrm{A}}$ and the early component of $I_{\mathrm{D}}$, preferentially control subthreshold responses to excitatory inputs and firing frequency (Debanne et al., 1997; Hille, 2001). Consistently, intracellular recordings from mPFC slices show that perfusion of either D1R-selective agonists or DA itself, but not D2R-selective agonists, reduces first spike latency, lowers firing threshold, and increases firing frequency, but does not alter the shape of the action potential (Yang and Seamans, 1996).

\section{Mechanism of DA D1R modulation}

Our studies indicate that D1Rs modulate $I_{\mathrm{D}}$ by activation of the AC/cAMP/PKA signal transduction pathway. Low concentrations $(0.1 \mu \mathrm{M})$ of D1R agonists induced similar inhibition, which was abolished by the D1R-selective antagonist SCH 23390 (1 $\mu \mathrm{M})$. Increasing intracellular cAMP levels with either forskolin or Sp-cAMP mimicked D1R-mediated inhibition of $I_{\mathrm{D}}$, suggesting that stimulation of the AC/cAMP/PKA pathway is sufficient to modulate $I_{\mathrm{D}}$. Neutralization of either cAMP or PKA, with RpcAMP and PKI, respectively, abolished D1R-induced inhibition of $I_{\mathrm{D}}$, suggesting that the AC/cAMP/PKA pathway is essential in D1R-mediated modulation. Phosphorylation is a common mechanism by which membrane channel proteins are subject to modification. Indeed, phosphorylation-induced inhibition of several types of $\mathrm{K}^{+}$channels has been reported in many other systems (for review, see Levitan, 1988).

The actions of DA on mPFC pyramidal neurons have long been controversial. Why does DA increase excitability in some situations while decreasing it in others? Our study suggests that DA can influence the activity of mPFC pyramidal neurons by modulation of VGKCs. Activation of DA D1Rs can increase neuronal excitability by inhibition of VGKC, whereas both D1R and D2R stimulation can suppress IRKC (Dong and White, 2001), but DA may also decrease whole-cell sodium current to decrease excitability (Maurice et al., 2001). Clearly, the actions of DA on $\mathrm{mPFC}$ pyramidal neurons depend on the timing and strength of synaptic inputs as well as on the membrane potential range at which mPFC neurons are operating (Yang et al., 1999).

\section{References}

Bekkers JM, Delaney AJ (2001) Modulation of excitability by $\alpha$-dendrotoxinsensitive potassium channels in neocortical pyramidal neurons. J Neurosci 21:6553-6560.

Berger B, Gaspar P, Verney C (1991) Dopaminergic innervation of the cerebral cortex: unexpected differences between rodents and primates. Trends Neurosci 14:21-27.

Bjorklund A, Divac I, Lindvall O (1978) Regional distribution of catecholamines in monkey cerebral cortex, evidence for a dopaminergic innervation of the primate prefrontal cortex. Neurosci Lett 7:115-119.

Cantrell AR, Smith RD, Goldin AL, Scheuer T, Catterall WA (1997) Dopaminergic modulation of sodium current in hippocampal neurons via cAMP-dependent phosphorylation of specific sites in the sodium channel $\alpha$ subunit. J Neurosci 17:7330-7338.

Cantrell AR, Scheuer T, Catterall WA (1999) Voltage-dependent neuromodulation of $\mathrm{Na}^{+}$channels by D1-like dopamine receptors in rat hippocampal neurons. J Neurosci 19:5301-5310.

Carr DB, Sesack SR (2000) Projections from the rat prefrontal cortex to the ventral tegmental area: target specificity in the synaptic associations with mesoaccumbens and mesocortical neurons. J Neurosci 20:3864-3873.

Carr DB, O'Donnell P, Card JP, Sesack SR (1999) Dopamine terminals in the rat prefrontal cortex synapse on pyramidal cells that project to the nucleus accumbens. J Neurosci 19:11049-11060.

Coetzee WA, Amarillo Y, Chiu J, Chow A, Lau D, McCormack T, Moreno H, Nadal MS, Ozaita A, Pountney D, Saganich M, Vega-Saenz DM, Rudy B
(1999) Molecular diversity of K+ channels. Ann NY Acad Sci 868:233-285.

Debanne D, Guerineau NC, Gahwiler BH, Thompson SM (1997) Actionpotential propagation gated by an axonal $\mathrm{I}(\mathrm{A})$-like $\mathrm{K}+$ conductance in hippocampus. Nature 389:286-289.

Dong Y, White FJ 2001 Dopamine (DA) modulation of $\mathrm{K}^{+}$currents in prefrontal cortex neurons: effects of chronic cocaine. Soc Neurosci Abstr 27:1578.

Emson PC, Koob GF (1978) The origin and distribution of dopaminecontaining afferents to the rat frontal cortex. Brain Res 142:249-267.

Foehring RC, Surmeier DJ (1993) Voltage-gated potassium currents in acutely dissociated rat cortical neurons. J Neurophysiol 70:51-63.

Fuster JM (2001) The prefrontal cortex-an update: time is of the essence. Neuron 30:319-333.

Gaspar P, Bloch B, Le Moine C (1995) D1 and D2 receptor gene expression in the rat frontal cortex: cellular localization in different classes of efferent neurons. Eur J Neurosci 7:1050-1063.

Geijo-Barrientos E, Pastore C (1995) The effects of dopamine on the subthreshold electrophysiological responses of rat prefrontal cortex neurons in vitro. Eur J Neurosci 7:358-366.

Goldman-Rakic PS, Muly III EC, Williams GV (2000) $D_{1}$ receptors in prefrontal cells and circuits. Brain Res Rev 31:295-301.

Gorelova N, Yang CR 1997 Dopamine D1 receptor stimulation modulates a slowly inactivating $\mathrm{Na}^{+}$current in layer V-VI prefrontal cortex neurons. Soc Neurosci Abstr 23:1771.

Gulledge AT, Jaffe DB (1998) Dopamine decreases the excitability of layer V pyramidal cells in the rat prefrontal cortex. J Neurosci 18:9139-9151.

Heinemann SH, Rettig J, Graack HR, Pongs O (1996) Functional characterization of Kv channel beta-subunits from rat brain. J Physiol (Lond) 493:625-633.

Hille B (2001) Ionic channels of excitable membranes. Sunderland, MA: Sinauer.

Hoffman DA, Johnston D (1999) Neuromodulation of dendritic action potentials. J Neurophysiol 81:408-411.

Holmqvist MH, Cao J, Knoppers MH, Jurman ME, DiStefano PS, Rhodes KJ, Xie Y, An WF (2001) Kinetic modulation of Kv4-mediated A-current by arachidonic acid is dependent on potassium channel interacting proteins. J Neurosci 21:4154-4161.

Hoshi T, Zagotta WN, Aldrich RW (1990) Biophysical and molecular mechanisms of Shaker potassium channel inactivation. Science 250:533-538.

Kirsch GE, Drewe JA (1993) Gating-dependent mechanism of 4-aminopyridine block in two related potassium channels. J Gen Physiol 102:797-816.

Knable MB, Weinberger DR (1997) Dopamine, the prefrontal cortex and schizophrenia. J Psychopharmacol 11:123-131.

Korngreen A, Sakmann B (2000) Voltage-gated K+ channels in layer 5 neocortical pyramidal neurones from young rats: subtypes and gradients. J Physiol (Lond) 525:621-639.

Levitan IB (1988) Modulation of ion channels in neurons and other cells. Annu Rev Neurosci 11:119-136.

Lewis DA (1995) Neural circuitry of the prefrontal cortex in schizophrenia. Arch Gen Psychiatry 52:269-272.

Locke RE, Nerbonne JM (1997) Three kinetically distinct $\mathrm{Ca}^{2+}$ independent depolarization-activated $\mathrm{K}+$ currents in callosal-projecting rat visual cortical neurons. J Neurophysiol 78:2309-2320.

Martina M, Schultz JH, Ehmke H, Monyer H, Jonas P (1998) Functional and molecular differences between voltage-gated $\mathrm{K}+$ channels of fastspiking interneurons and pyramidal neurons of rat hippocampus. J Neurosci 18:8111-8125.

Maurice N, Tkatch T, Meisler M, Sprunger LK, Surmeier DJ (2001) $D_{1} / D_{5}$ dopamine receptor activation differentially modulates rapidly inactivating and persistent sodium currents in prefrontal cortex pyramidal neurons. J Neurosci 21:2268-2277.

Miller EK, Cohen JD (2001) An integrated theory of prefrontal cortex function. Annu Rev Neurosci 24:167-202.

Murakoshi H, Trimmer JS (1999) Identification of the Kv2.1 K+ channel as a major component of the delayed rectifier $\mathrm{K}+$ current in rat hippocampal neurons. J Neurosci 19:1728-1735.

Nicola SM, Surmeier DJ, Malenka RC (2000) Dopaminergic modulation of neuronal excitability in the striatum and nucleus accumbens. Annu Rev Neurosci 23:185-215. 
Sawaguchi T, Goldman-Rakic PS (1991) D1 dopamine receptors in prefrontal cortex: involvement in working memory. Science 251:947-950.

Seamans JK, Floresco SB, Phillips AG (1998) $D_{1}$ receptor modulation of hippocampal-prefrontal cortical circuits integrating spatial memory with executive functions in the rat. J Neurosci 18:1613-1621.

Sesack SR, Pickel VM (1992) Prefrontal cortical efferents in the rat synapse on unlabeled neuronal targets of catecholamine terminals in the nucleus accumbens septi and on dopamine neurons in the ventral tegmental area. J Comp Neurol 320:145-160.

Sibley DR, Monsma FJ Jr (1992) Molecular biology of dopamine receptors. Trends Pharmacol Sci 13:61-69.

Stoof JC, Kebabian JW (1984) Two dopamine receptors: biochemistry, physiology and pharmacology. Life Sci 35:2281-2296.

Surmeier DJ, Kitai ST (1993) $D_{1}$ and $D_{2}$ dopamine receptor modulation of sodium and potassium currents in rat neostriatal neurons. In: Chemical signaling in the basal ganglia (Arbuthnott GW, Emson PC, eds), pp 309324. Amsterdam: Elsevier.

Surmeier DJ, Stefani A, Foehring RC, Kitai ST (1991) Developmental regulation of a slowly-inactivating potassium conductance in rat neostriatal neurons. Neurosci Lett 122:41-46.

Surmeier DJ, Eberwine J, Wilson CJ, Cao Y, Stefani A, Kitai ST (1992) Dopamine receptor subtypes colocalize in rat striatonigral neurons. Proc Natl Acad Sci USA 89:10178-10182.

Tzschentke TM (2001) Pharmacology and behavioral pharmacology of the mesocortical dopamine system. Prog Neurobiol 63:241-320.

Undie AS, Berki AC, Beardsley K (2000) Dopaminergic behaviors and signal transduction mediated through adenylate cyclase and phospholipase C pathways. Neuropharmacology 39:75-87.

Vanderschuren LJMJ, Kalivas PW (2000) Alterations in dopaminergic and glutamatergic transmission in the induction and expression of behavioral sensitization: a critical review of preclinical studies. Psychopharmacology 151:99-120.

Vincent SL, Khan Y, Benes FM (1995) Cellular colocalization of dopamine $D_{1}$ and $D_{2}$ receptors in rat medial prefrontal cortex. Synapse 19:112-120.

Williams GV, Goldman-Rakic PS (1995) Modulation of memory fields by dopamine D1 receptors in prefrontal cortex. Nature 376:572-575.

Yang CR, Seamans JK (1996) Dopamine D1 receptor actions in layers V-VI rat prefrontal cortex neurons in vitro: modulation of dendritic-somatic signal integration. J Neurosci 16:1922-1935.

Yang CR, Seamans JK, Gorelova N (1999) Developing a neuronal model for the pathophysiology of schizophrenia based on the nature of electrophysiological actions of dopamine in the prefrontal cortex. Neuropsychopharmacology 21:161-194.

Zahrt J, Taylor JR, Mathew RG, Arnsten AF (1997) Supranormal stimulation of $\mathrm{D}_{1}$ dopamine receptors in the rodent prefrontal cortex impairs spatial working memory performance. J Neurosci 17:8528-8535.

Zhang X-F, Hu X-T, White FJ (1998) Whole-cell plasticity in cocaine withdrawal: reduced sodium current in nucleus accumbens neurons. J Neurosci 18:488-498.

Zhou FM, Hablitz JJ (1996) Layer I neurons of the rat neocortex. II. Voltagedependent outward currents. J Neurophysiol 76:668-682. 